\title{
Catastrophic Mechanism and Stability Analysis of Jiangdingya Landslide in Zhouqu County, Gansu Province, China
}

\author{
Tianzhong Ma ${ }^{1}$, Xiaohui Yang*1, Weixiong Zhang ${ }^{2}$ and Chendong Sun ${ }^{1}$ \\ ${ }^{1}$ School of Civil Engineering, Lanzhou University of Technology \\ ${ }^{2}$ Gansu Geological Disaster Prevention Engineering Exploration and Design Institute, China
}

*Corresponding author: DR Xiaohui Yang, Lanzhou University of Technology, China.

\begin{abstract}
On July 12, 2018, a large-scale landslide occurred in the Jiangdingya area, Nanyu Town, Gansu Province, China. According to remote sensing interpretation and field investigation, the landslide volume is about $480 \times 104-550 \times 104 \mathrm{~m}^{3}$, which caused the Bailongjiang River to be blocked and the water level to rise, forming a dammed lake, flooding Nanyu Town. The landslide is characterized by chain disasters, which poses a serious threat to the ecological security of the upper reaches of the Yangtze River. In this paper, the catastrophic mechanism of Jiangdingya landslide is analyzed, and the stability of the slope is studied. According to the disaster characteristics, comprehensive safety control measures are put forward. The research results of this paper are of great significance to the prevention and control of chain disasters and the comprehensive treatment of slopes.
\end{abstract}

Keywords: Landslide; Catastrophic mechanism; Stability analysis

\section{Introduction}

China is one of the countries with serious landslide disasters in the world. Due to the special landform and geological environment conditions, landslide disasters occurred every year in history. There are nearly one million geological disaster points in China, among which there are more than 34,000 serious geological disaster points. Nearly 1,000 people die every year due to geological disasters, and the direct economic loss is 20 billion yuan. The annual cost of landslide remediation of the state is as high as 50 million yuan [1]. The Zhouqu County of Gansu Province is located in the south of the West Qinling tectonic belt, with high mountains and deep valleys, well-developed geological structure and strong neotectonic movement, which is a seismic prone area. The rock mass in this area is broken, the structure is loose, the slope is large, the geological environment is fragile, and the soil erosion is serious
It is one of the areas with high incidence of landslides, collapses, and mudslides in China. There is a high frequency of resurrection of landslides in this area, such as Xieliupo landslide, Nanyu landslide, Suoertou landslide and so on. At present, some landslides continue to deform and cause new disasters. At about 17:00 on June 13, 1991, the Jiangdingya landslide of Nanyu Landslide Group in Nanyu Town, Zhouqu County, Gansu Province, China, experienced a largescale sliding [2-5] The lower part of the landslide body was firstly sheared and destroyed, then slowly declined, and instantly blocked the Bailongjiang River. Then, the upper part of the landslide mass was pulled to slide rapidly. The huge thrust of landslide soil and the jacking action of the steep wall on the other side of the Bailongjiang River made the sliding tongue of the sliding body climb along the steep wall, and finally form an earth dam with a height of $20 \mathrm{~m}$ and 
a width of $50 \mathrm{~m}$. As a result, the Bailongjiang River is cut off for up to 8 hours, the backwater in the upper reaches of Bailongjiang River is about $2.8 \mathrm{~km}$, and the accumulated water is $754.9 \times 104$ m3. Half of the Nanyu Town is submerged, and the loss is serious [6]. In the following years, the Jiangdingya landslide was basically stable. At about 8: 00 on July 12, 2018, the Jiangdingya ancient landslide was reactivated. The reactivated Jiangdingya landslide (H1 landslide) belongs to the local part of Jiangdingya ancient landslide (H landslide) The earthwork volume of landslide reached $480 \times 104-550 \times 104 \mathrm{~m} 3$, which caused the Bailongjiang River to be blocked and the water level to rise. The Jiangdingya landslide has the characteristics of chain disaster, which not only threatens the safety of Nanyu Town, but also interrupts the safe operation of roads and hydropower stations. The blocking of large-scale rivers will endanger the safety of the Zhouqu County in the upper reaches and Longnan City in the lower reaches. It will also pose a serious threat to the ecological security of the upper reaches of the Yangtze River with immeasurable losses. Therefore, the study of landslide development characteristics and formation mechanism has gradually become one of the core problems and hot issues in landslide disaster research.

\section{Natural Geological Structure}

The Jiangdingya ancient landslide is located in Nanyu Town, Zhouqu County, Gannan Tibetan Autonomous Prefecture, Gansu Province, China. The geographic coordinate of the landslide is $104^{\circ} 25^{\prime} 7^{\prime \prime} \sim 104^{\circ} 25^{\prime} 47^{\prime \prime}$ E and $33^{\circ} 43^{\prime} 03^{\prime \prime} \sim 33^{\circ} 43^{\prime} 43^{\prime \prime}$ N. Zhouqu County is located in the eastern edge of Qinghai-Tibet Plateau, where the west wing of West Qinling meets Minshan Mountains. The elevation of the top of the mountain is $2052 \mathrm{~m}$, the elevation of the foot of the slope is $1241 \mathrm{~m}$, the relative height difference is $811 \mathrm{~m}$, and the topography fluctuates greatly. The Boiling River passes from the northwest to the southeast from the front edge of the slope The Jiangdingya ancient landslide is located in the upper part of the slope body with a gradient of about $20^{\circ}$. The topography of the slope surface fluctuates greatly. The rear part of the sliding body is depression, and tensile cracks and shear cracks are developed in the middle, lower part and front edge, forming drumlins locally. The leading edge has been obviously transformed by human engineering activities, and a scarp with a slope of $45^{\circ}$ is formed by manual excavation. The exposed strata of the Jiangdingya landslide from bottom to top are: Bailongjiang River group of Middle-Upper Silurian system (S2+3bl1), Gudaoling formation of Xihan Water group of Middle Devonian system (D $2 \mathrm{~g})$, Upper Carboniferous System $(\mathrm{C} 2+3)$, Holocene old landslide deposits (Q4del), and Holocene proluvial (Q4al+pl).According to the post-disaster investigation, there is no water in the middle part of the landslide, but there is water in the back and middle front part, which indicates that there has not been a unified aquifer after the landslide. Because the gray-black gravel clay in the landslide belongs to the relative water-resisting layer, there is stagnant water in the upper part of the slope. There is a "water gathering effect" on the upper part of the sliding surface, and the groundwater mainly occurs in the layer of gravelly soil. The existence of groundwater in the sliding body reduces the cohesion and internal friction angle of the slope and increases the instability of the sliding body. The temperature change in the region is small, and the temperature difference between day and night is small. The average rainfall is $400-800 \mathrm{~mm}$, the maximum daily rainfall is $96.7 \mathrm{~mm}$, and the maximum rainfall in one hour is $77.3 \mathrm{~mm}$. With the increase of altitude, precipitation also increases. Human activities in the Jiangdingya landslide area are mainly manifested in two aspects: cutting slope to build roads and gentle slope cultivation, which reduced the stability of the slope of the ancient landslide body.

\section{Evolution History of Landslide}

The Jiangdingya landslide (H1 landslide) is the reactivated body in the middle of the Jiangdingya ancient landslide (H landslide) of Nanyu landslide group, and it has been in sliding state. In the year of 1986, 1988, 1990 and 1991, there were four large-scale sliding events on the Jiangdingya slope, and the river was blocked in the last three times, which caused extremely serious losses [2]. Among them: on September 11, 1990, The Jiangdingya ancient landslide slipped. Millions of cubic meters of landslide pushed the road at the foot of the mountain to the middle of Bailongjiang River. The soil in Bailongjiang River was as high as $5 \sim 15 \mathrm{~m}$, and the river was partially blocked, and the water level of the river rose and flooded farmland. On June 13, 1991, about 5.3 million cubic meters of soil slipped down from the landslide, blocking the Bailongjiang River for 8 hours, and the upstream backwater was about $2.8 \mathrm{~km}$, which forced Nanyu township to select a site for the reconstruction and suffered serious loss. The resurrection landslide (H1 landslide) in 2018 has a maximum length of about $462 \mathrm{~m}$, an average width of about $210 \mathrm{~m}$, an average thickness of about $26.5 \mathrm{~m}$, and a total volume of $338.1 \times 104 \mathrm{~m} 3$. It is a large-scale landslide.

\section{Development Characteristics of Jiangdingya Landslide}

The reactivation body (H1 landslide) of the Jiangdingya ancient landslide is a large-scale sliding accumulation landslide. The rear and middle parts of $\mathrm{H} 1$ landslide are relatively gentle, about $13^{\circ}$ to $15^{\circ}$, the lower part and front edge are relatively steep, about $20^{\circ}$ to $25^{\circ}$.After $\mathrm{H} 1$ landslide slides, steep walls are formed at the back and both sides of the landslide mass, and the side and back walls are distributed in the shape of "circle chair". In the longitudinal direction, the thickness of the landslide is thicker in the middle and upper part, followed by the rear part, and the middle and the front part is thinner. The sliding zone soil is mainly gray-black gravelly clay, and the soil is soft plastic and saturated. The scratches on the surface of sliding zone soil are obvious. The lithology of the sliding bed is the accumulation of the ancient landslide, which is yellow brown with a thickness of about $20 \sim 50 \mathrm{~cm}$, and is mainly composed of limestone gravels, block stones and carbonaceous slate fragments. 


\section{Analysis of Catastrophe Mechanism of Landslides}

According to the remote sensing image of landslide, the sliding distance at the back of landslide is $89.57 \mathrm{~m}$, that in the middle is $87.31-97.25 \mathrm{~m}$, and that in the front is $29.79-90.47 \mathrm{~m}$ the sliding distance decreases in turn, which indicates that when the middlerear block slides down, it is blocked by the front block, the sliding speed slows down. The results show that the sliding mass belongs to the deep deformation of push type landslide. According to the analysis of slip time, the landslide began to slide at 8:00 on July 12, 2018 and stopped at 9:00 on July 13, 2018, the sliding time lasted for 25 hours. The average sliding distance of the landslide mass is $65.76 \mathrm{~m}$, and the moving distance per hour is $2.63 \mathrm{~m} / \mathrm{t}$, which indicates that the landslide is mainly characterized by push-type with slow deformation. The Jiangdingya landslide was formed under the coupling action of endogenic and exogenic dynamic forces. The geological structure of Bailongjiang River basin is complex, weathering and groundwater activities have an obvious softening effect on landslide soil, which makes the Jiangdingya ancient landslide always in the creep deformation state. Tectonic activities, rock properties and terrain conditions are the internal factors of landslide. The appropriate terrain slope provides necessary potential energy and material accumulation for the development and formation of landslide. The tectonic stress of a certain mode and intensity is the external dynamic factor of landslide, and the earthquake is an important factor to induce landslide and collapse. Heavy rain is the main inducing factor in the revival of the Jiangdingya landslide. Atmospheric precipitation and river erosion increase the water content of slope, weaken the mechanical properties of rock and soil, and reduce the stability of slopes. The intervention of human engineering activities has changed the existing environment of landslide, affected the stability of the landslide, and finally aggravated the sliding instability of landslide (Figure 1).

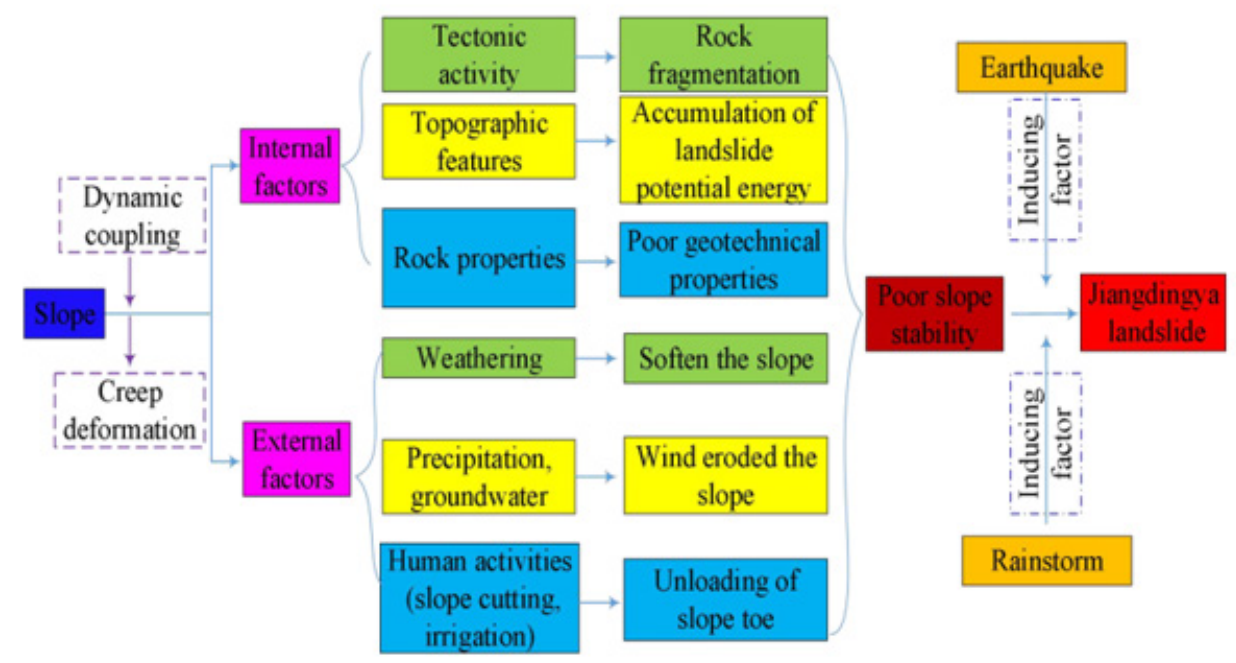

Figure1: Catastrophe mechanism of landslide.

\section{Stability Analysis of Landslide}

Table 1: Summary of theoretical calculation results of landslide stability.

\begin{tabular}{|c|c|c|}
\hline Calculation Condition & Stability Coefficient & Stable State \\
\hline working condition i: self-weight action & 1.195 & stable \\
\hline working condition ii: self-weight action + rainstorm action & 0.979 & unstable \\
\hline working condition iii: self-weight action+ earthquake action & 1.014 & unstable \\
\hline
\end{tabular}

The landslide is simulated and analyzed by MIDAS GTS, the soil adopts Mohr Coulomb constitutive model, and the supporting structure adopts linear elastic constitutive model. The simulation is divided into two stages. In the first stage, the stability of the section $1-1$ ' of the slope is calculated, and only the boundary conditions and self-weight load are activated. The calculation working conditions are as follows: working condition I: self-weight action. Working condition II: self-weight action + rainstorm action. Working condition III: self-weight action + earthquake action. The rainstorm standard is the rainstorm intensity with a return period of 50 years. The fortification intensity of Zhouqu County is degree, and the peak ground motion acceleration is $0.2 \mathrm{~g}$. The stability calculation results are shown in Table 1. It can be seen that the landslide is in a stable state under natural conditions, and the stability of the slope will be reduced to a certain extent under the influence of earthquake or heavy rainfall. Under the action of continuous precipitation, the 
gravity of the upper soil mass of the landslide increases, and the groundwater in the landslide body cannot be discharged in time, thus forming a large hydrodynamic pressure in the landslide soil, increasing the sliding force and reducing the stability. Therefore, Considering the complexity and harmfulness of the landslide, comprehensive treatment is carried out by adopting anchor cable lattice engineering, anti-slide pile engineering, interception and drainage engineering and slope crack treatment engineering (Table 1).

\section{Safety Treatment of Landslide}

The upper slope is the unstable part of the landslide mass, and the horizontal displacement of the upper slope suddenly increases to $20 \mathrm{~cm} \sim 50 \mathrm{~cm}$. The lower slope can basically keep stable under the natural state without external disturbance. The deformation of the upper slope is effectively constrained after the anchor cable lattice is set, which indicates that the anchoring engineering effectively strengthens the unstable rock and soil mass and limits its deformation. In addition, the reinforced concrete lattice beam plays an auxiliary role in retaining soil and dispersing the anchoring force. The anti-slide pile set in the lower slope provides greater shear bearing capacity to the originally weak sliding surface by passing through the pile body of the sliding surface.

\section{Conclusion}

In this paper, the catastrophic mechanism and stability analysis of Jiangdingya landslide are studied, according to the characteristics of disasters, the comprehensive safety control scheme is put forward, the following conclusions are obtained:

1. The Jiangdingya landslide is formed under the coupling effect of endogenic and exogenic dynamic forces. The deformation of the front edge of the landslide is mainly traction collapse. The upper part of the landslide is affected by groundwater infiltration and sliding force, and the main deformation is creep deformation. In general, the thrust from the upper part of the landslide is greater than the traction force in the front part of the landslide, the Jiangdingya landslide belongs to sliding-traction landslide.

2. The Jiangdingya landslide is affected by the fault zone, with broken rock mass and special topography accumulating landslide potential energy, which provides conditions for landslide sliding. The geological environment in Jiangdingya area determines the diversity, susceptibility and regional variability of geological disasters.

3. The occurrence of the Jiangdingya landslide is closely related to the superposition of geological structure, environmental evolution, precipitation infiltration, earthquake damage and human activities. Among them, the geological structure is the decisive factor, and earthquake and rainstorm are the inducing factors.
4. The Jiangdingya slope is in a creep state under the coupling effect of endogenic and exogenic dynamic forces. Precipitation infiltration and agricultural irrigation increase the water content of slope and weaken the shear strength of slope continuously. The water erosion has continuously weakened the stability of the slope, which easily leads to the revival of new large-scale landslide.

5. In view of Jiangdingya landslide, risk management measures should be taken to identify the landslide disaster risk, strengthen mass prevention and treatment, strengthen landslide early warning, and avoid the recurrence of major geological disasters.

6. Under the influence of earthquake or heavy rainfall, the stability of slope will be reduced to a certain extent. The comprehensive treatment of anchor cable lattice structure engineering, anti-slide pile engineering, interception and drainage engineering and slope crack treatment engineering has a positive effect on landslide disaster prevention and ecological restoration.

\section{Acknowledgment}

The authors gratefully acknowledge financial support from the Innovation Fund Program of Gansu provincial bureau of geology and mineral resources (Grant No. 2020CX09) and National Science Foundation of China (Grant No. 52068048) and we thank the financial support from and Industrial support program of Research Fund for Disaster Mechanism and Comprehensive Prevention Technology of Landslide of High and Large Accumulation Body in the Marginal Area of Qinghai-Tibet Plateau.

\section{Conflict of Interest}

No conflict of interest.

\section{References}

1. Zhou C, Yin K, Cao Y, Ahmed B (2016) Application of time series analysis and PSO-SVM model in predicting the Bazimen landslide in the Three Gorges Reservoir, China. Eng Geol 204: 108-120.

2. Chen HT (1991) Brief introduction to NanYu big landslide, Zhouqu County, Gansu. NW Hydropower 4: 63-63 (in Chinese).

3. $\mathrm{Mu} \mathrm{P}$ (2011) Analysis on causes and stability of landslide at Jiangdingya in Zhouqu County of Gansu Province. China Water Resourc (4): 50-52 (in Chinese).

4. Wang JR, Qi L, Cai XX (1994) Analysis on landslide of Nanyu in Zhouqu County of Gansu Province. Bull Soil Water Conserv 14(1): 57-60 (in Chinese).

5. Ren JZ (1993) The Nanyu landslip and small earthquake activity. NW Seisgeol J 15(2): 94-96 (in Chinese).

6. Huang X, Yang WM, Zhang CS, Shen JF, Liu T (2013) Deformation Characteristics and Formation Mechanism of Xieliupo Landslide in Zhouqu. Journal of Geomechanics 19(2): 178-187 (in Chinese). 